\begin{tabular}{|c|c|c|}
\hline institute & $\begin{array}{l}\text { CARADDE: Jurnal Pengabdian Kepada Masyarakat } \\
\text { https://journal.ilininstitute.com/index.php/caradde } \\
\text { Volume } 2 \text { | Nomor 1 | Agustus | 2019 } \\
\text { e-ISSN: } 2621-7910 \text { dan p-ISSN: 2621-7961 } \\
\text { DOI: } \text { https://doi.org/10.31960/caradde.v2i1.110 }\end{array}$ & $\begin{array}{l}\text { IIN } \\
\text { CARADOE }\end{array}$ \\
\hline
\end{tabular}

\title{
Workshop Saham Syariah Bagi Mahasiswa dan UMKM di Banjarmasin Untuk Meningkatkan Minat Berinvestasi Saham Syariah
}

\author{
Purboyo $^{1}$, Rizka Zulfikar ${ }^{2}$, Syahrani ${ }^{3}$, Kumara Efrianti ${ }^{4}$
}

\begin{tabular}{ll}
\hline \hline Keywords : & Abstrak. Tujuan kegiatan ini adalah (1) memberikan \\
Workshop; & pengetahuan kepada peserta tentang pasar modal syariah dan \\
Saham Syariah; & cara berinvestasi secara legal dan aman, (2) memberikan \\
Investasi; & keterampilan dan kemampuan kepada peserta untuk mampu \\
UMKM. & menganalisa saham syariah yang baik dengan menganalisa \\
& laporan keuangan perusahaan, (3) memberikan keterampilan \\
Corespondensi Author & dan kemampuan kepada peserta untuk dapat langsung \\
Fakultas Ekonomi, Universitas Islam & bertransaksi dipasar modal.Pelaksanaan kegiatan pengabdian \\
Kalimantan (Uniska) - MAB & masyarakat berupa workshop tentang saham syariah ini \\
Banjarmasin & dengan metode ceramah, diskusi, pengenalan saham syariah, \\
Jalan Adhyaksa Banjarmasin & keunggulan saham syariah, bagaimana cara menganalisa \\
Email:mail.purboyo@gmail.com & laporan keungan perusahaan untuk memilih saham yang baik \\
& dan juga dilakukan praktek simulasi bertransaksi saham \\
History Artikel & syariah. Peserta kegiatan berjumlah 25 orang yang terdiri dari \\
Received: Januari-2019; & 13 mahasiswa dan 12 pengusaha UMKM yang ada di \\
Reviewed: April-2019 & Banjarmasin.. Hasil pelaksanaan kegiatan adalah 88\% \\
Accepted: April-2019 & peserta berminat untuk berinvestasi disaham syariah dan \\
Published: Juni-2019 & bersedia menjadi investor disaham syariah dan melakukan \\
& pendaftaran untuk menjadi investor. Hasil evaluasi kinerja \\
& kegiatan memberikan hasil mayoritas peserta memberikan \\
& penilaian sangat baik kepada kemampuan pembicara dalam \\
& menyampaikan materi, isi materi, suasana pelatihan serta \\
& sarana dan prasarana yang ada. \\
\hline
\end{tabular}

This work is licensed under a Creative Commons Attribution

4.0 International License

\section{PENDAHULUAN}

Diera ekonomi modern saat ini banyak masyarakat yang mempunyai keinginan untuk berinvestasi, namun tidak sedikit yang justru terjebak kedalam investasi bodong atau ilegal yaitu investasi yang tidak mempunyai ijin dari lembaga Otoritas Jasa Keuangan (OJK). Hal ini karena masih lemahnya pengetahuan masyarakat tentang produk investasi yang aman dan hanya tergiur dengan iming-iming imbal hasil yang tinggi.

Beberapa kasus investasi ilegal yang cukup menghebohkan di Banjarmasin dengan kerugian yang cukup besar sempat tercatat yaitu kasus investasi berkedok penjualan voucher ditahun 2003 dan kasus investasi berlian oleh pengusaha berlian bernama lihan ditahun 2010 dengan kerugian mencapai milyaran rupiah seperti diberitakan serambi ummah Banjarmasin Post di laman http://banjarmasin.tribunnews.com tanggal 12 Nopember 2016. Bahkan menurut keterangan Tongam L.Tobing selaku ketua satgas investasi OJK kerugian akibat investasi illegal dikatakan bahwa "Jumlah perkiraannya mencapai $\mathrm{Rp}$ 105,8 triliun dalam kurun waktu 10 tahun terakhir, ini 
sangat besar." (Laucereno, 2018). Berdasarkan kasus investasi ilegal diatas maka sosialisasi dan edukasi tentang produkproduk investasi yang legal dan aman perlu terus diberikan kepada masyarakat agar kerugian akibat investasi ilegal dapat di minimalkan. Salah satu produk investasi yang legal dan relatif aman yang perlu terus disosialisasikan adalah produk investasi saham di Bursa Efek Indonesia (BEI). BEI dalam hal ini selaku pengelola pasar saham telah membuat gerakan Yuk Nabung Saham (YNS) guna memberikan kesempatan yang seluas-luasnya kepada masyarakat menjadi investor dipasar modal dengan membeli saham secara rutin dan berkala.

Saham yang di perdagangkan di BEI selain saham konvensional juga terdapat Saham syariah, saham syariah adalah saham di pasar modal yang tidak bertentangan dengan prinsip syariah, prinsip syariah adalah prinsip hukum Islam dimana dalam kegiatan di pasar modal berdasarkan fatwa Dewan Syariah Nasional (DSN) - Majelis Ulama Indonesia (MUI), sepanjang fatwa tersebut tidak bertentangan dengan peraturan Otoritas Jasa Keuangan (POJK No.15 tahun 2015).

Saham syariah mempunyai beberapa keunggulan dibanding saham konvensional diantaranya investasinya halal, bebas dari unsur-unsur maisir, gharar dan riba (Hanif, 2012). Kinerja keuangan saham syariah juga cukup baik, terutama saham-saham yang tergabung dalam kelompok saham syariah Jakarta Islamic Index (JII) dimana selama kurun waktu tahun 2013 sampai tahun 2016 tercatat bahwa kinerja keuangan sahamsaham syariah tersebut cukup baik sehingga dapat dijadikan pilihan dalam berinvestasi (Purboyo dan Zulfikar, 2017).

Uniska MAB Banjarmasin selaku perguruan tinggi yang bercirikan islam mempunyai tanggung jawab untuk memajukan ekonomi islam atau lebih dikenal dengan ekonomi syariah, berkaitan dengan hal tersebut maka memberikan pendidikan atau pelatihan tentang investasi saham syariah menjadi sebuah keniscayaan. Mahasiswa dan pelaku Usaha Mikro Kecil Menegah (UMKM) merupakan sasaran tepat untuk diberikan pendidikan dan pelatihan tentang bagaimana berinvestasi saham syariah dipasar modal sehingga diharapkan kedepanya muncul investor-investor yang berwawasan ekonomi syariah.

Untuk meningkatkan minat berinvestasi di pasar modal salah satunya adalah dengan menyelenggarakan pelatihan atau workshop, karena workshop mampu meningkatkan minat seseorang terhadap sesuatu yang diharakan memberi manfaat pada dirinya (Sudanta, 2015). Dengan katan lain dengan diadakannya workshop tentang pasar modal syariah diharapkan dapat meningkatkan minat berinvestasi disaham syariah.

Pelaksanaan kegiatan pengabdian masyarakat berupa workshop tentang saham syariah ini dengan metode ceramah, diskusi, pengenalan saham syariah, keunggulan saham syariah, cara menganalisa laporan keungan perusahaan untuk memilih saham yang baik dan teknik serta praktek simulasi bertransaksi saham syariah. Peserta kegiatan berjumlah 25 orang yang terdiri dari 13 mahasiswa dan 12 pengusaha UMKM yang ada di Banjarmasin. Tujuan kegiatan ini adalah (1) memberikan pengetahuan kepada peserta untuk berinvestasi secara legal dan aman, (2) memberikan keterampilan dan kemampuan kepada peserta untuk mampu menganalisa saham yang baik dengan menganalisa laporan keuangan perusahaan, (3) memberikan keterampilan dan kemampuan kepada peserta untuk dapat langsung bertransaksi dipasar modal dengan gerakan yuk nabung saham sehingga diharapkan kedepan tercipta investor-investor yang berwawasan ekonomi syariah.

\section{METODE}

Kegiatan pengabdian kepada masyarakat ini dilaksanakan dibulan Desember 2018, dengan metode pelaksanaan kegiatan melalui tahapan yaitu: (1) tahapan persiapan, (2) tahapan kegiatan, dan (3) tahapan evaluasi kegiatan. Tahapan persiapan dilakukan dengan melakukan survey pendahuluan ketempat mitra, hal ini dilakukan untuk mengetahui kesediaan mitra bekerja sama dengan tim pengusul, menentukan tempat dan waktu pelaksanaan, menentukan jumlah peserta, khalayak sasaran dari kegiatan ini dan mendiskusikan tema kegiatan yang akan dilaksanakan. 
Tahapan kegiatan yaitu terdiri dari kegiatan-kegiatan selama workshop berlangsung yaitu:

\section{Ceramah dan Diskusi}

Dalam ceramah dan diskusi disampaikan dan dipandu oleh dosen-dosen yang berkompeten di bidang investasi saham syariah dan dalam kegiatan ini juga diundang hadir dari pihak Bursa Efek Indonesia wilayah Kalimantan Selatan. Materi yang disampaikan mengenai edukasi pasar modal dan edukasi saham syariah dan bagaimana menganalisa saham dengan pendekatan Fundamental analisis.

\section{Materi Fundamental Analisis dan Teknikal} Analisis

Fundamental analisis merupakan metode analisis saham dengan menganalisa kinerja keuangan perusahaan melalui beberapa rasiorasio pada laporan keuangan, rasio-rasio tersebut antara lain Return On Equity (ROE), Debt to Equity Ratio (DER), Book Value, Price to Book Value (PBV), Earning Per Share (EPS), Price to Earning Ratio (PER), dengan tujuan untuk mengetahui bagaimana korelasi antara harga saham dengan keadaan perusahaan sehingga investor dapat mengetahui mana saham yang baik secara value(Sinaga \& Triaryati, 2014).

Tehnikal Analisis merupakan metode analisis saham dengan mengidentifikasi pola dan tren harga saham dengan cara mempelajari data pasar masa lampau, terutama pergerakan saham dan volume sehingga dapat diprediksi suatu pergerakan harga saham dimasa yang akan datang dengan tujuan untuk bahan pertimbangan saat akan membeli atau menjual saham (Reka et.all., 2014), dalam tekhnikal analisis ini peserta diajarkan melihat grafik yang sudah ada di sistem dan melhat sinyal kapan saat yang tepat untuk membeli saham.

Workshop merupakan suatu proses kegiatan belajar secara kelompok, peserta melakukan praktek langsung untuk lebih memahami dan mengenal suatu masalah (Djajendra, 2015). Workshop juga dapat diartikan sebagai pelatihan yang meliputi teori dan praktek dalam satu kegiatan terintegrasi (Sugianto, 2012). Dalam kegiatan workshop ini para peserta juga diberikan pengetahuan dengan media visual tentang teknik-teknik bertransaksi saham syariah dipasar modal dan dititik beratkan pada pemahaman tentang Fundamental Analisis (FA) sehingga saham yang dipilih merupakan saham dari perusahaan yang mempunyai kinerja keuangan yang baik.

\section{Cara berinvestasi di saham syariah.}

Dalam kegiatan praktek berinvestasi saham syariah didemonstrasikan cara transaksi langsung dengan menggunakan trading online system dengan aplikasi system trading saham syariah dari perusahaan sekuritas yang ada, sistem ini telah di desain untuk dapat bertransaksi secara syariah dimana saham-saham yang dapat di transaksikan melalui sistem ini hanya sahamsaham syariah.

Berikut ini adalah contoh beberapa tampilan sistem yang ada di aplikasi saham syariah pada perusahaan Phintraco sekuritas. Phintraco sekuritas adalah perusahaan sekuritas yang bekerja sama dengan galeri investasi Uniska MAB Banjarmasin.

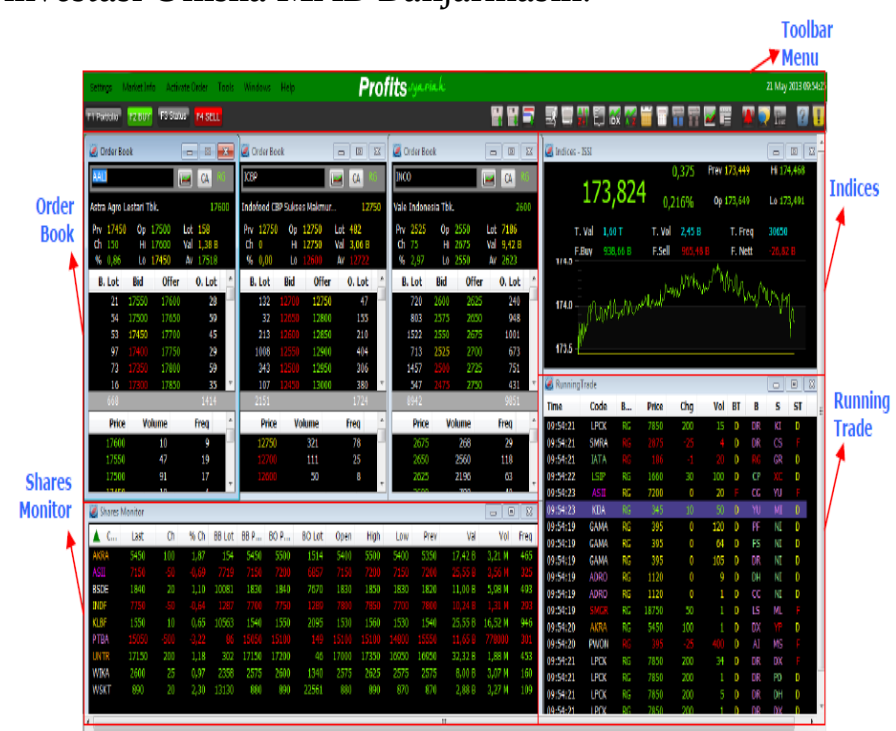

Gambar 1. Tampilan simulasi pasar saham 
Caradde: Jurnal Pengabdian Kepada Masyarakat

Vol 2 No 1, Agustus 2019

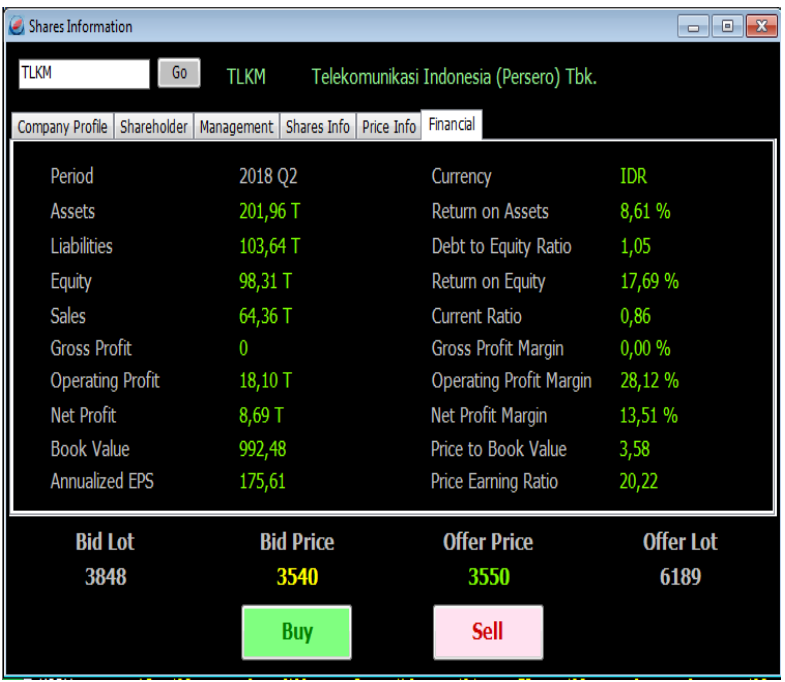

Gambar 2. Fundamental analisis salah satu saham.

\section{HASIL DAN PEMBAHASAN}

\section{Tahap Persiapan}

Pada tahap persiapan ini dilakukan dalam dua kali pertemuan bersama mitra yakni:

Pertemuan pertama dilakukan pada tanggal 5 Desember 2018 dengan berkunjung ke lokasi usaha mitra di RM. Ayam Kudus untuk membicarakan maksud dan tujuan tim pengusul mengadakan kegiatan pengabdian kepada masyarakat.

Pertemuan kedua pada tanggal 15 Desember 2018 untuk memastikan waktu pelaksanaan dan tempat kegiatan, jumlah peserta, sasaran dan khalayak peserta kegiatan.

\section{Waktu, Tempat dan Peserta Kegiatan}

Kegiatan dilaksanakan pada tanggal 22 Desember 2018 sejak pukul 09.00 sampai dengan pukul 12.30 WITA, bertempat di Rumah Makan Ayam Kudus yang berada di Jalan Raya Gatot Subroto Banjarmasin yang diikuti oleh 25 peserta. Kegiatan pengabdian kepada masyarakat ini dihadiri oleh Wakil Dekan III Fakultas Ekonomi Universitas
Islam Kalimantan MAB Banjarmasin yakni Bapak Syahrani, SE, MM untuk memberikan kata sambutan sekaligus membuka secara resmi kegiatan pengabdian kepada masyarakat ini.

\section{Tahap Pelaksanaan}

Tahap pelaksanaan kegiatan dilakukan dengan beberapa metode yakni penyampaian materi workshop melalui ceramah dan diskusi,Dalam ceramah dan diskusi disampaikan materi-materi penting seputar pasar modal dan edukasi tentang pasar modal, mengenal saham syariah, caramudah menjadi investor saham syariah, menganalisa saham dan bagaimana bertransaksi saham. Di paparkan juga beberapakeunggulan saham syariah, bagaimana menjadi investor saham, bagaimana menganalisa saham dengan melakukan analisa fundamental perusahaan yaitu mempelajari laporan keuangan perusahaan yang menerbitkan saham dan mempelajari pergerakan saham melalui grafik tekhnikal analisis.

\section{Bimbingan menjadi investor}

Pada tahap ini bagi peserta yang telah memahami dan berminat untuk menjadi investor disaham syariah dilakukan bimbingan bagaimana cara mengisi formulir untuk membuka Rekening Dana Nasabah (RDN) dan melengkapi syarat-syarat yang diperlukan agar bisa aktif sebagai investor. Dari 25 peserta yang megikuti kegiatan ini terdapat 22 peserta yang berminat dan bersedia menjadi investor di saham syariah, sehingga jika di prosentasekan terdapat $88 \%$ peserta yang berminat menjadi investor.Selanjutnya bagi peserta yang mendaftar menjadi investor akan disampaikan ke pihak BEI Kalsel untuk bimbingan lanjutan dikemudian hari, sehingga investor baru akan mempunyai pengetahuan yang lebih dalam tentang investasi di saham syariah. 

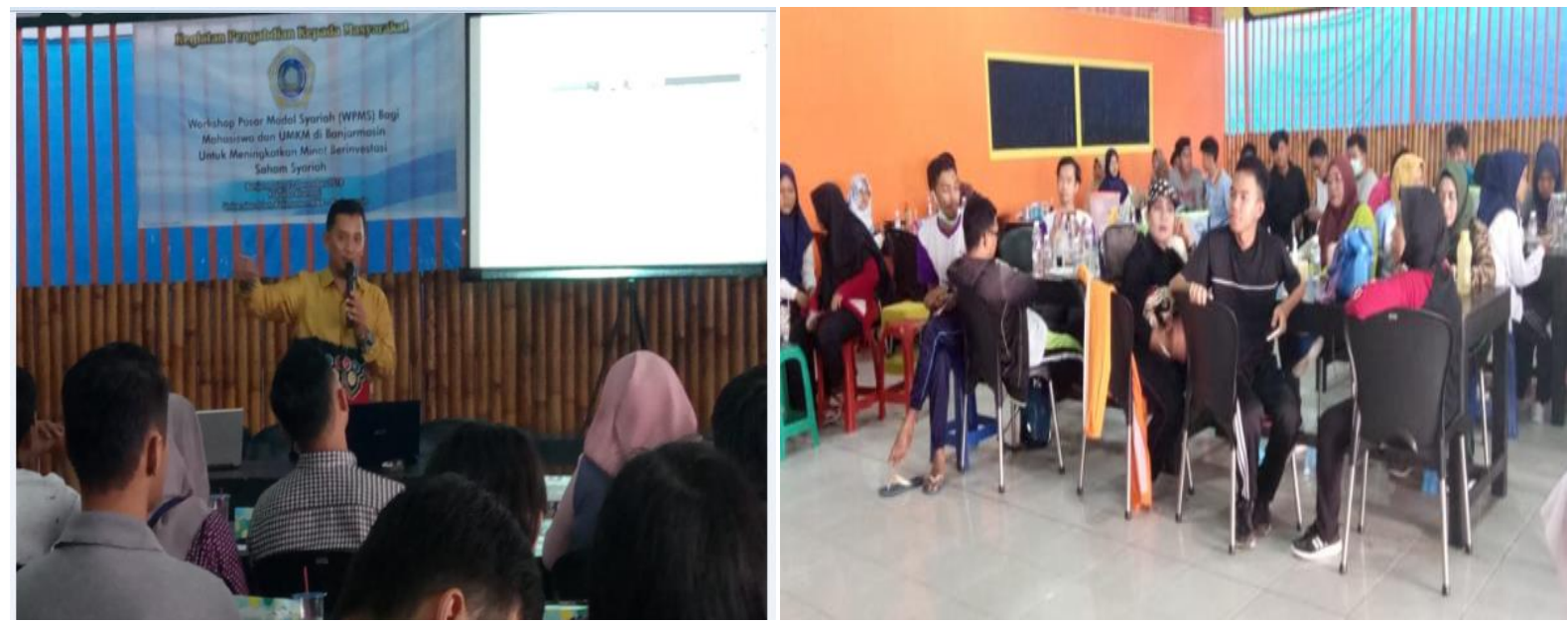

Gambar 3. Penyampaian materi, ceramah dan diskusi

\section{Evaluasi Kegiatan}

Untuk menilai keberhasilan hasil kegiatan pengabdian kepada masyarakat ini, maka evaluasi yang dilakukan adalah dengan memberikan kuesioner tentang penilaian peserta terhadap pelaksanaan kegiatan yang berkaitan tentang kualitas pembicara, bahan materi, suasana dan prasarana kegiatan. Hasil evaluasi kegiatan menujukkan bahwa mayoritas peserta memberikan penilaian baik.

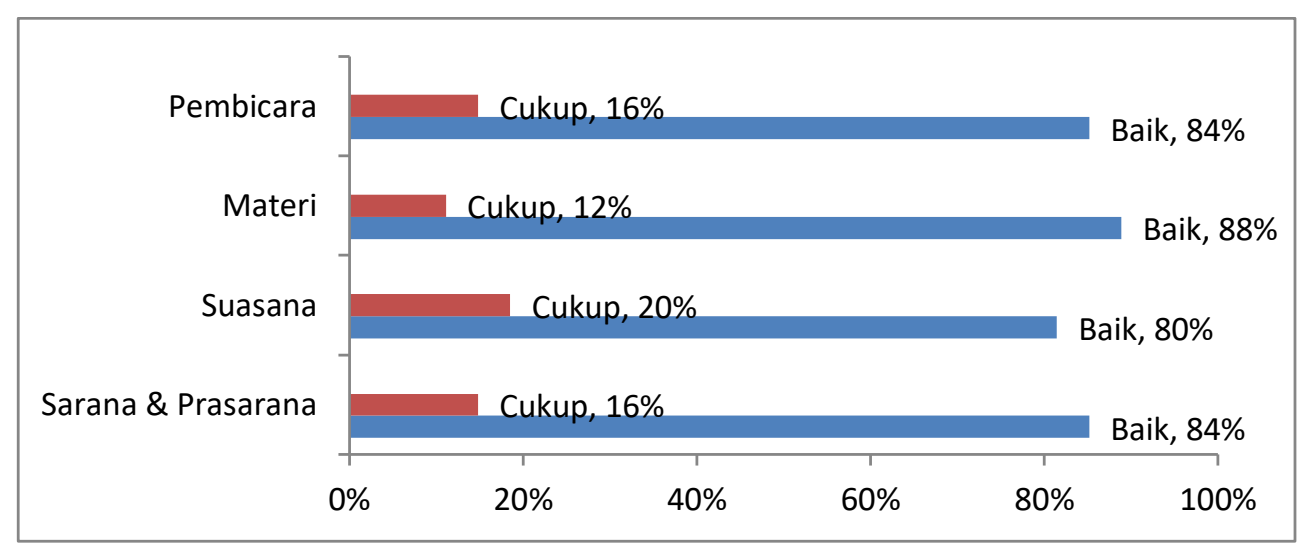

\section{Grafik 1. Hasil evaluasi kegiatan}

\section{SIMPULAN DAN SARAN}

Meningkatnya minat peserta untuk berinvestasi disaham syariah, hasil pelaksanaan kegiatan adalah $88 \%$ peserta berminat untuk berinvestasi disaham syariah dan bersedia menjadi investor disaham syariah dengan melakukan pendaftaran untuk menjadi investor.

Hasil evaluasi kinerja kegiatan memberikan hasil mayoritas atau sebagian besar peserta memberikan penilaian sangat baik kepada kemampuan pembicara dalam menyampaikan materi, isi materi, suasana pelatihan serta sarana dan prasarana.

Diharapkan pelatihan dan sosialisasi pasar modal terus dilakukan agar masyarakat melek terhadap pasar modal, khususnya tentang pasar modal syariah, sehingga dapat terhindar dari kegiatan investasi illegal.

\section{DAFTAR RUJUKAN}

Djajendra. 2015.Memahami Perbedaan Workshop, Training, Seminar, Dan Kelas Motivasi.Http://DjajendraMotivator.C om. Diakses Tanggal 24 Sep 2018.

Hanif, 2012. Perkembangan Perdagangan Saham Syariah di Indonesia. Jurnal ASAS Vol.2 no.1, Januari 2012.

Laucereno, S. F. (2018). Total Kerugian Akibat Investasi Bodong Tembus Rp 105,8 Triliun. Retrieved Desember 10, 2018 ,
fromDetik.Finance: 
https://finance.detik.com/moneter/d3750260/total-kerugian-akibat-investasibodong-tembus-rp-1058-triliun

Otoritas Jasa Keuangan. 2015. Penerapan Prinsip Syariah di Pasar Modal, Pub. L. No. 15/POJK.04/2015.

Purboyo, 2017. Sinyal Kinerja Profitabiltas, Solvabilitas dan Rasio Pasar yang Mempengaruhi Harga Saham Syariah di Jakarta Islamic Index (JII). Jurnal Owner Riset dan Akuntansi, Vo.1 no.2, Desember 2017.

Reka, D., Noer, A., Achsani, A., \& Sasongko, H. (2014). Analisis Fundamental, Teknikal Dan Makroekonomi Harga Saham Sektor Pertanian. Jurnal Manajemen Dan Kewirausahaan, 16(2), 175-184. https://doi.org/10.9744/jmk.16.2.175 -184 .
Sinaga, A. K., \& Triaryati, N. (2014). Pengaruh Faktor Fundamental dan Ekonomi Makro Terhadap Harga Saham. EJurnal Manajemen Universitas Udayana, 3(1), 1412-1426.

Sudanta, I. W. 2015. Efektivitas Kegiatan Workshop Dalam Meningkatkan Kemampuan Menetapkan Kriteria Ketuntasan Minimal (Kkm) Studi Kasus Pada Gugus Pejeng, Kec. Tampaksiring, Kab. Gianyar 2013-214. Jurnal DHARMASMRTI. 13 (26) : $75-84$.

Sugianto,

E.2012.Pengertian Training/Workshop dan Seminar. Http : //www.naqsdna .com/2012/03/pengertian-training workshop dan seminar.html. Diakses tanggal 24 Sep 2018. 